\title{
ESTUDO PETROLÓGICO DE ALGUNS FRAGMENTOS TECTÔNICOS DA MELANGE OFIOLÍTICA EM ABADIÂNIA (GO): III - TEXTURAS E COMPOSIÇÃO QUIIMICA DOS CORPOS MÁFICOS
}

\author{
ADELIR J. STRIEDER* \& ARIPLÍNIO A. NILSON**
}

\begin{abstract}
PETROLOGICAL STUDY OF SOME TECTONIC FRAGMENTS OF THE OPHIOLITIC MELANGE DST THE ABADIÂNIA (GO): III - TEXTURES AND CHEMICAL COMPOSITION OF THE MAFIC BODIES. Four large mafic bodies outcrop in the Abadiânia region. The bodies were strongly deformed and metamorphosed together with the metasedimentary sequence were they are tectonically emplaced. This mafic bodies study embraces the description and the analysis of their petrographic features and, later, the evaluation of their petrochemistry and the tectonic setting where they come from. The petrographic analysis showed textura! evidences that permited to indicate the estability of an unique metamorphic assemblage in the observed deformational phases, define the metamorphic temperature $\left(550-600^{\circ} \mathrm{C}\right)$ and pressure $(>5 \mathrm{kbar})$ conditions, and suggest a gabbroic protolith instead of a volcanic one. In this way, a chemical investigation was put foward to evaluate the occurence of cumulative processes in the original rock, since these processes could have modified the chemical composition and, consequently, may change the procedures used to investigate the geochemical affinity of them. No cumulative effects were observed and, thus, a serie of minor element diagrams were used to indicate their geochemical affinity and geotectonic setting. By this approach, it is suggested that the mafic rocks outcroping in the Abadiânia region display a high-K tholeiitic basalt affinity and represent rocks of a island-arc setting. The intimate relationship to serpentinite bodies of harzburgitic composition show that mafic bodies may have originally been part of a complete ophiolite sequence, but are presently tectonic fragments in the ophiolitic melange identified in Goiás State.
\end{abstract}

Keywords: Mafic rocks petrochemistry, Abadiânia melange ophiolitic fragments, Goiás, Brazil.

\begin{abstract}
RESUMO Quatro grandes corpos máficos afloram na região de Abadiânia. Eles foram intensamente deformados e metamorfizados com as rochas metassedimentares onde estão tectonicamente alojados. Este estudo dos corpos máficos abrange uma ampla descrição e análise das suas feições petrográficas e, posteriormente, uma investigação da sua natureza petroquímica e do posicionamento tectônico de onde derivam. A análise petrográfica revelou evidências texturais que permitiram identificar a estabilidade de uma mesma paragênese metamórfica principal nas fases deformacionais observadas, definir as condições de temperatura $\left(550-600^{\circ} \mathrm{C}\right)$ e de pressão $(>5 \mathrm{kbar})$ do metamorfismo e sugerir um protolito gabróico, ao invés de vulcânico, para os corpos máficos. A partir desta última característica, foi realizada uma investigação química para avaliar a ocorrência de processos acumulativos, já que eles podem Ter modificado a composição química do magma inicial e, conseqüentemente, mudar os procedimentos para avaliar a afinidade geoquímica destas rochas. Como nenhum efeito de processos acumulativos foi observado, um grupo de diagramas petroquímicos que empregam elementos menores e traços foi usado para indicar a sua afinidade geoquímica e o seu posicionamento tectônico original. Por este procedimento, sugere-se que as rochas máfícas da região de Abadiânia possuem afinidade com basaltos toléiticos de alto-K e representam rochas formadas em sistemas de arcos-de- ilhas. A Ultima associação com os corpos de serpentinito de natureza harzburgítica mostra que os corpos máficos podem ter sido originalmente parte de uma seqüência ofiolítica completa, mas, hoje, fazem parte da melange ofiolítica identificada no Estado de Goiás.
\end{abstract}

Palavras-chaves: Petroquímica de rochas básicas, fragmentos ofiolíticos da melange de Abadiânia, Goiás, Brasil.

INTRODUÇÃO Os corpos máficos que ocorrem alojados nos metassedimentos Araxá têm recebido um tratamento um tanto casual em diversos trabalhos de caráter regional desenvolvidos no Estado de Goiás (Corrêa \& Bittencourt 1968, Batista 1969, Nilson et al 1969, Berbert et al 1970, Araújo et al 1980), talvez devido à ausência imediata de mineralizações. De um modo geral, eles receberam uma atenção muito menor do que a dispensada aos corpos de serpentinito, pois raramente se teve $p$ cuidado de definir a extensão, a petrografia, ou mesmo o quimismo daqueles corpos.

Este artigo é a terceira parte de uma série que procura descrever todos os aspectos estruturais e petrográficos e analisar a composição geoquímica de alguns dos litotipos encaixados nos metassedimentos Araxá. A preocupação de estudar estas rochas decorre da caracterização desta associação como uma melange ofiolítica (Strieder \& Nilson 1991); com isso, pode-se começar a definir alguns pontos da evolução do posicionamento geotectônico da melange ofiolítica descrita inicialmente na região de Abadiânia.
O artigo apresenta, portanto, uma detalhada caracterização petrográfica de quatro corpos máficos reconhecidos na região de Abadiânia (GO) e de treze pequenos corpos recentemente identificados na região de Ipameri (Dardenne et al 1992). A partir da caracterização petrográfica, são discutidas as modificações texturais, as relações de equilíbrio de fases minerais diante do metamorfismo e, ao final, o caráter petroquímico dos corpos.

MÉTODOS ANALÍTICOS As análises químicas de elementos maiores e menores (Tab. 1) das rochas básicas foram realizadas no Laboratório de Geoquímica da Universidade de Brasília através do método via-úmida [metodologia especificada por Boaventura \& Hirson (1987)] e por espectometria de plasma (ICP). Os elementos tracos (Tab. 2) e terras raras (Tab. 3) foram respectivamente analisados através de fluorescência de raios X e espectrometria de plasma (ICP) na Divisão de Laboratórios da GEOSOL. Em ambos os laboratórios, a utilização de amostras em duplicata mostrou uma reprodutibilidade muito boa das análises.

\footnotetext{
* Centro de Estudos em Petrologia e Geoquímica, Instituto de Geociências, Universidade Federal do Rio Grande do Sul, Avenida Bento Gonçalves, 9500, Caixa Postal 15001, CEP 91501-970, E-mail: Adelir@DFl.UFRGS.BR, Porto Alegre, RS, Brasil

** Departamento de Mineralogia e Petrologia, Instituto de Geociências, Universidade Federal de Brasília, Asa Norte, CEP 70910-900, Brasília, DF, Brasil
} 
Tabela 1 -Análise química de elementos maiores (\% peso) e menores (ppm) dos litotipos que compõem os corpos máficos. Amostras assinaladas com * correspondem aos corpos máficos da região de Ipameri (Dardenne et al. 1992)

Table 1 - Chemical analysis of major ( $\mathrm{wt} \%$ ) and minor (ppm) elements of the lithotypes forming the mafic bodies. Labelled samples $(*)$ are firom Ipameri region mafic bodies (Dardenne et al. 1992)

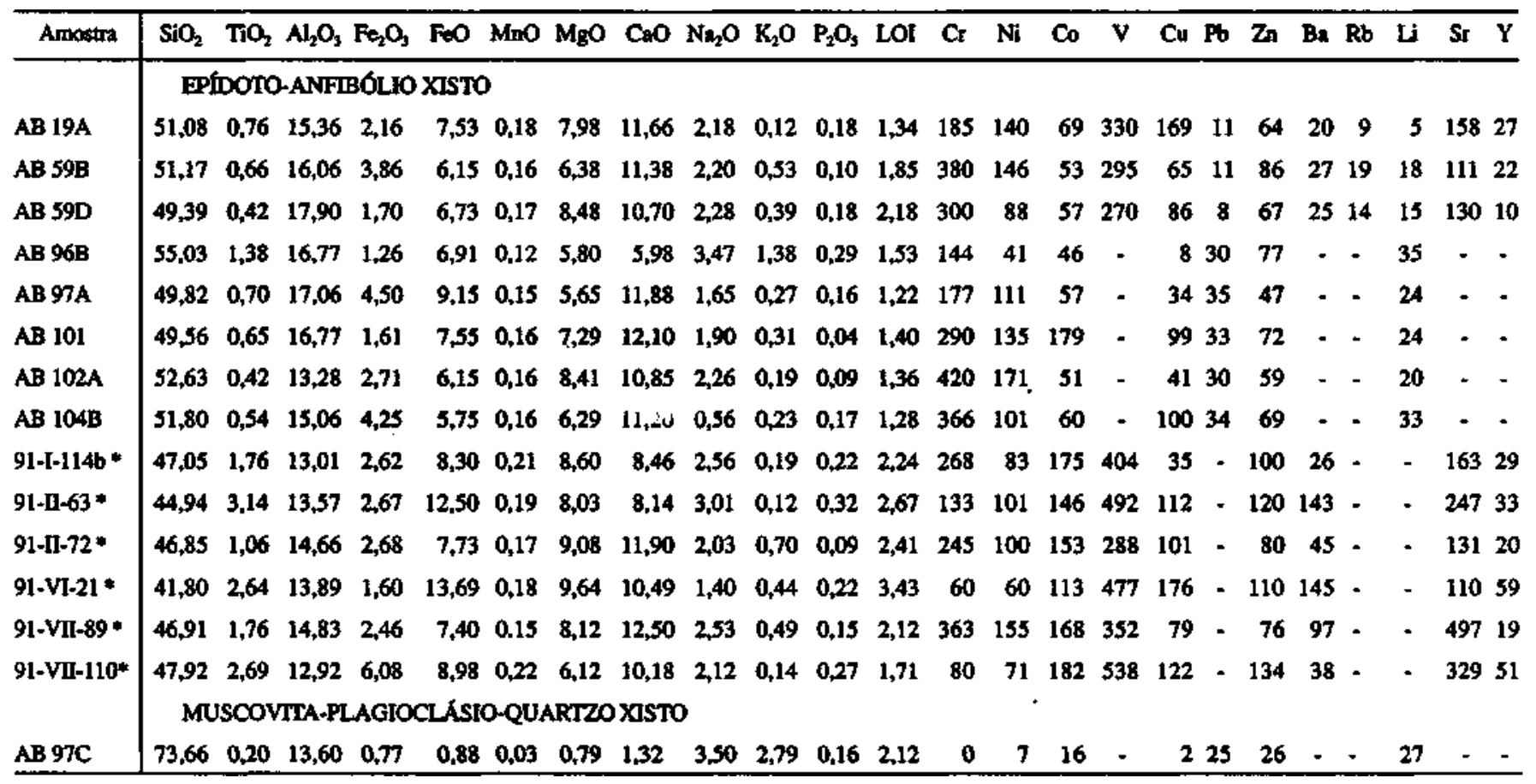

Tabela 2 - Análises de elementos traços (ppm) de amostras de epídoto-anfibólio xisto

Table 2 - Trace elements analysis (ppm) of the epidote-amphibole schist samples

\begin{tabular}{l|cccccc}
\hline Amostra & Ba & V & Y & Nb & Zr & Sr \\
\hline AB 59B & 27,00 & 295,00 & 22,50 & 23,00 & 93,00 & 111,00 \\
AB19A & 20,00 & 330,00 & 27,00 & 24,00 & 108,00 & 158,00 \\
AB 59D & 25,00 & 270,00 & 10,00 & 24,00 & 86,00 & 130,00 \\
\hline
\end{tabular}

Tabela 3-Análises de ETR (ppm) de epídoto-anfibólio xisto

Table 3 - REE chemical analysis (ppm) of the epidote-amphibole schist

\begin{tabular}{c|ccccccccccc}
\hline Amostra & La & Ce & Sm & Yb & Nd & Eu & Gd & Dy & Er & Lu & Ho \\
\hline AB 59B & 4,40 & 7,40 & 1,75 & 1,85 & 6,95 & 0,83 & 2,80 & 3,45 & 2,35 & 0,27 & 0,72 \\
AB 19A & 2,70 & 5,50 & 1,80 & 2,30 & 6,80 & 0,87 & 3,00 & 3,80 & 2,60 & 0,33 & 0,81 \\
AB 59D & 3,00 & 5,10 & 1,40 & 1,60 & 6,20 & 0,79 & 2,50 & 3,00 & 1,90 & 0,24 & 0,60 \\
\hline
\end{tabular}

\section{CARACTERIZAÇÃO PETROGRÁ RCA DOS CORPOS}

MÁFICOS Os corpos máficos que ocorrem na região de Abadiânia possuem uma área aflorante que pode alcançar $10-12 \mathrm{~km}^{2}$ (Fig. 1, Strieder \& Nilson 1992); os corpos máficos identificados na região de Ipameri (GO), no entanto, possuem área aflorante predominante semelhante àquela dos corpos de serpentinito $\left(0,4 \mathrm{~km}^{2}\right)$. Do mesmo modo que os corpos de serpentinito, os corpos máficos aparecem em posições estruturais bem definidas ao longo dos segmentos de deformação e possuem uma compatibilidade bem marcada entre a sua deformação interna e a deformação impressa nas rochas metassedimentares encaixantes (Strieder 1990). Estas características gerais fizeram com que os corpos máficos não fossem tratados separadamente na análise estrutural, nem recebessem denominações específicas para o tratamento petroquímico.
Os corpos máficos são predominantemente formados por uma rocha denominada epídoto-anfibólio xisto. Na verdade, este termo é usado de uma maneira genérica para designar uma rocha de caráter básico, cuja composição mineralógica varia entre anfibólio xisto e epídoto xisto com feldspato. De um modo mais restrito, também ocorre um muscovita-plagioclásioquartzo xisto, que aparece em "bandas" de escala decimétrica a métrica paralelizadas com o epídoto-anfibólio xisto pelo desenvolvimento da xistosidade $\mathrm{S}_{1}$.

Macroscopicamente, a xistosidade $S_{\}}$do epídoto-anfibólio xisto está muito bem desenvolvida; ela marca um bandamento milimétrico, que não se traduz, necessariamente, na alternância de colorações contrastantes, mas, mais propriamente, no aspecto assumido frente à alteração diferencial. Em alguns casos (Foto 1), no entanto, é possível observar finas 
bandas de coloração mais clara, descontínuas (lentículas muito alongadas), com bordos salientes e angulares, onde grãos de quartzo, ou de feldspato têm um tamanho maior do que a espessura média da lentícula e são reconhecidos como ciastos rema-nescentes. No lado norte do Corpo de Serpentinito CS9 (região de Abadiânia), identificou-se a passagem gradual de um epídoto-anfibólio xisto fino, como descrito acima, para uma rocha com bandamento mais grosso e com foliação de caráter anastomosado em torno de pequenas lentes; estas lentes pos-suem aspecto de augen de espessura $>3 \mathrm{~mm}$ e que são essencialmente constituídas por minerais máficos. $\mathrm{Na}$ região de Ipameri (GO), identificou-se corpos máficos que preservam uma textura fanerítica fina-média variavelmente deformada; esta textura indica um protolito gabróico para os corpos máficos.

A textura fanerítica do protolito gabróico é predominantemente formada por anfibólio em prismas curtos (1-3 $\mathrm{mm}) \mathrm{e}$ grossos. Estes prismas não têm qualquer orientação preferencial; freqüentemente, os grãos se interceptam e deixam espaços triangulares a losangulares, onde estão localizados o plagioclásio, o epídoto, a biotita, algum quartzo, a titanita e os minerais opacos. A textura geral é fanerítica média, mas lembra uma textura sub-ofítica determinada pelos grãos de anfibólio. $\mathrm{O}$ anfibólio tem pleocroísmo de verde amarelado claro $\left(\mathrm{n}_{\mathrm{x}}\right)$ a verde oliva $\left(\mathrm{n}_{\mathrm{z}}\right)$ e possui núcleo com muitas inclusões pulverulentas de minerais opacos, que delimitam formas prismáticas curtas a anédricas; estas formas englobam parcialmente ripas de plagioclásio em textura sub-ofítica. Em alguns casos, o núcleo destas formas é o próprio anfibólio verde oliva, mas com orientação ótica diferente daquela do bordo. Isto parece sugerir que o anfibólio verde oliva substituiu um mineral ígneo primário, possivelmente um pirpxênio. O plagioclásio primário está completamente reequilibrado para uma paragênese do tipo epídoto+plagioclásio sódico; apesar disto, pode-se perceber o hábito ripiforme $(1,0-1,5 \mathrm{~mm})$ do plagioclásio primário.

Microscopicamente, o bandamento milimétrico de $\mathrm{S}_{\mathrm{t}}$ é determinado pela concentração diferencial dos minerais metamórficos em três distintas paragêneses: 1) quartzo+albita, 2) mica branca \pm quartzo + albita + epídoto e 3) biotita \pm quartzo \pm albita \pm epídotcH-actinolita. Pode-se observar, ainda, outra diferenciação através da formação de níveis centimétricos onde se alternam as bandas quartzo+albita e mica branca \pm quartzo+ albita+epídoto e as bandas mica branca \pm quartzo+albita + epídoto e biotita \pm quartzo \pm albita \pm epídoto + actinolita. Em maior escala, esta diferenciação pode estar refletida na variação modal entre os termos ricos em epídoto ou em anfibólio.

A textura predominante do epídoto-anfibólio xisto é nematoblástica fina; porém, a presença mais acentuada de quartzo, de albita e de mica branca gradativamente desloca as feições petrográficas para uma textura granoblástica irregular a elongada. No epídoto-anfibólio xisto junto ao Corpo de Serpentinito CS9, lentes grossas de minerais máficos são predominantemente formadas por actinolita (augen) com formas sigmoidais e com variável desmembramento ao longo das clivagens (Foto 2); as lentes podem, ainda, possuir epídoto prismático curto que mostra granulação de bordo quando localizado nos bordos das lentes. Estas características permitem, então, identificar uma textura ultramilonítica inicial para o epídoto-anfibólio xisto; o tamanho dos clastos de actinolita e de epídoto diminui muito com a intensidade da xistosidade $\mathrm{Sj}$, mas, feita a observação inicial, é possível reconhecê-los em algumas outras amostras (Foto 3).

O quartzo e a albita ocorrem em cristais xenoblásticos finos com contatos suturados. $\mathrm{O}$ epídoto $(0,1-0,8 \mathrm{~mm})$, por sua vez, aparece sob duas formas: a. clinozoisita equidimensional fina, que sempre está relacionada com as bandas de quartzo+albita; e b. epídoto prismático curto, que aparece nas bandas de textura nematoblástica, ou que ocorre como porfiroclastos com sombra de pressão.
A actinolita tem fórmula pleocróica em verde azulado $\left(n_{z}\right)$ e em verde amarelado a acastanhado claro $\left(\mathrm{n}_{\mathrm{x}}\right)$ e possui hábito prismático curto a alongado com tamanho médio entre $1,0 \mathrm{e}$ $2,0 \mathrm{~mm}$. Como porfiroclasto, a actinolita atinge $4,0 \mathrm{~mm}$ e, não raro, comporta inclusões de epídoto, de quartzo, ou de albita.

As micas aparecem em associações distintas. A biotita ocorre em plaquetas pouco espessas com tamanho $<0,5 \mathrm{~mm}$ e está relacionada às bandas com predomínio da actinolita, com a qual mantém contatos retilíneos de equilíbrio. A mica branca, por sua vez, ocorre em plaquetas normalmente mais espessas do que a biotita (tamanho entre 0,3 e $0,9 \mathrm{~mm}$ ) e está relacionada às bandas com predomínio de epídoto.

Os muscovita+plagioclásio+quartzo xistos, como referido acima, ocorrem paralelizados aos epídoto-anfibólio xistos pelo desenvolvimento da xistosidade $\mathrm{S}_{1}$, o que pode resultar em um bandamento decimétrico bem marcado. Microscopicamente, apresentam textura granoblástica irregular predominante; porém, o aumento da quantidade de muscovita faz com que o quartzo e o plagioclásio mostrem um hábito mais alongado (textura granoblástica elongada). O quartzo e o plagioclásio são difíceis de serem distinguidos, possuem hábito xenoblástico a alongado e têm tamanho da ordem de 0,2-0,3 $\mathrm{mm}$. O plagioclásio pode, em alguns casos, ser observado como feno blastos com tamanho até $20 \mathrm{~mm}$ e com geminados finos mal desenvolvidas; estes grãos são o resultado da completa recristalização de antigos porfiroclastos. O quartzo alongado mostra lamelas de deformação bem desenvolvidas. A muscovita que marca a xistosidade $\mathrm{S}_{1}$ ocorre como cristais espessos com tamanho entre 0,5 e $0,8 \mathrm{~mm}$ e com extinção ondulante.

A transposição pela xistosidade $S_{2}$ é identificada em apenas um local, onde há a formação de um bandamento entre o epídoto-anfibólio xisto e o muscovita-plagioclásio-quartzo xisto; nos demais casos, a superfície $\mathrm{S}_{2}$ é identificada apenas como clivagem de crenulação ou como plano axial de meso e microdobras.

Da mineralogia que marca a xistosidade $\mathrm{S}_{1}$, apenas a actinolita e as micas são perfeitamente identificadas como recristalizadas ao longo da superfície $\mathrm{S}_{2}$. A actinolita pode ser dividida em dois grupos: a. cristais com hábito acicular e com tamanho até $1,0 \mathrm{~mm}$, que são aparentemente formados pela destruição mecânica da actinolita grossa relacionada a $\mathrm{S}_{1}$, ou dos porfiroclastos de actinolita anterior a $\mathrm{S}_{1}$; e b. cristais com hábito prismático curto e com tamanho entre 0,4 e $0,6 \mathrm{~mm}$, que estão orientados segundo $S_{2}$ e que truncam as formas de actinolita do grupo anterior. A biotita ocorre em lamelas finas de tamanho $<0,3 \mathrm{~mm}$ que pode truncar a actinolita cristalizada em $\mathrm{S}_{1}$. A transposição por $S_{2}$ levou ao desenvolvimento local de uma nova textura nematoblástica, mas deixa as charneiras de microdobras ainda preservadas.

As superfícies deformacionais $\mathrm{K}_{1}$ e $\mathrm{K}_{2}$ (região de Abadiânia) são registradas apenas na forma de fraturas densas, ou de clivagem de crenulação com espaçamento centimétrico, onde não é observado qualquer efeito evidente de recristalização; deste modo, não foi possível identificar microscopicamente uma trama metamórfico-deformacional para estas superfícies. Por outro lado, em alguns afloramentos (Foto 1), segregações de feldspato+clorita+quartzo foram observadas nos locais onde há um desajuste geométrico entre o extrado (dobras concêntricas abertas) e o intrado (crenulações centimétricas fechadas) das dobras $\mathrm{F}_{\mathrm{kl}}$; este tipo de segregação também foi observado em outras posições estruturais das rochas metassedimentares encaixantes (Strieder 1989, 1990). Na região de Ipameri, a superficie deformacional $\mathrm{S}_{3}$ foi registrada somente na forma de plano axial de crenulações suaves, o que também não permitiu identificar concretamente a paragênese metamórfica desta fase.

DISCUSSÃO SOBRE AS OBSERVAÇÕES PETRO-

GRÁFICAS $O$ registro de textura fanerítica nos corpos máficos da região de Ipameri (GO) vem reforçar a interpretação textural do protolito gabróico fornecida a partir da textura 

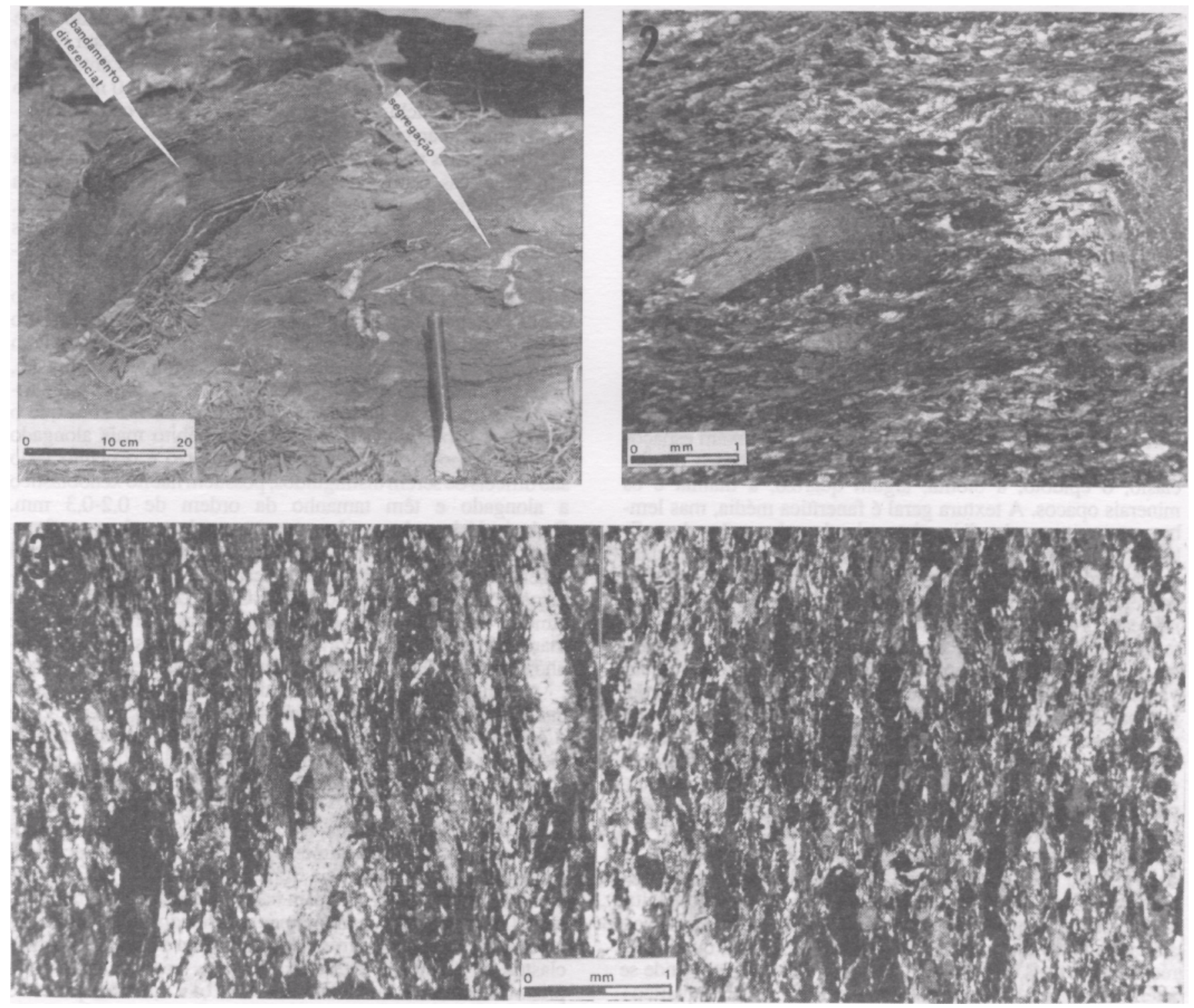

Prancha 1-1. Bandamento diferencial mm-cm dado por bandas descontínuas com porfiroclastos de quartzo e feldspato. Segregações de feldspato \pm clorita \pm quartzo nas porções onde a crenulação por $K_{1}$ é mais forte; 2. Augen (porfirodástico) de anfibólio em processo de desmembramento durante a formação da superficie $S_{1} ; 3$. Textura milonítica de $S_{l}$ com porfiroclastos finos de anfibólio e de epídoto

Plate 1 - 1. Discontinuous banding $(\mathrm{mm}-\mathrm{cm})$ by differential concentration of quartz and feldspar porphyroclasts. Feldspar \pm chlorite \pm quartz segregations located at strong $\mathrm{K}_{1}$ crenulations areas; 2 . Amphibole (prophyroclasüc) augen being dismembered during $\mathrm{S}_{1}$ development; $\mathbf{3}$. Ultramilonitic texture with small porphyroclasts of epidote and amphibole

ultramilonítica registrada na região de Abadiânia (Strieder 1989). No entanto, a textura fanerítica está pseudomorfizada pelos mesmos minerais metamórficos observados ao longo das xistosidade $\mathrm{S}_{1}$ e $\mathrm{S}_{2}$; isto indica que alguns corpos máficos estavam termicamente equilibrados com as rochas encaixantes, embora representem pods de baixa deformação. A caracterização petrográfica dos corpos máficos nas regiões de Abadiânia (Strieder 1989) e de Ipameri (Dardenne et al. 1992, Strieder 1990) permitiram o reconhecimento, a partir da textura fanerítica original, de texturas proto a ultramiloníticas, com predominância destas últimas. Considerado o protolito gabróico, pode-se sugerir, para protolito do muscovita-plagioclásio-quartzo xisto, injeções finais de plagiogranito. Assim, o reconhecimento de texturas miloníticas para a xistosidade $S_{1}$ permite estabelecer correlação deformacional com os litotipos encaixantes.

A milonitização de uma rocha gabróica de textura média pode, mais adequadamente, ser responsável pelo tipo de ban- damento descrito para o epídoto-anfibólio xisto, pois há uma tendência natural, frente a determinados mecanismos de milonitização, de ocorrer uma separação entre bandas de clastos e bandas de recristalização. Este mesmo mecanismo atuou sobre os gnaisses/xistos porfiroclásticos (granitos milonitizados) da região para formar bandamentos em diversas escalas (Strieder 1989,1990).

A paragênese metamórfica principal, quartzo \pm albita+epídoto+actinolita, mostra contatos cristalinos de equilíbrio entre todas as fases minerais da primeira superfície deformacional. A recristalização ao longo de $S_{2}$ faz aparecer a mesma paragênese metamórfica de $\mathrm{S}_{1}$; contudo, é interessante notar que os contatos corrosivos entre minerais relacionados a diferentes superfícies deformacionais são perfeitamente observados somente quando estão envolvidas diferentes fases minerais. Estas características também foram observadas em outros tipos litológicos da região (Strieder 1989) e parecem sugerir que todo o 
processo deformacional ocorreu dentro do campo de estabilidade da fácies epídoto-anfibolito.

A delimitação mais precisa do campo de estabilidade da paragênese metamórfica em termos das condições de $\mathrm{P}$ e de $\mathrm{T}$ está ligada à identificação das reações metamórficas que dão origem à paragênese considerada. No entanto, pelas características petrográficas discutidas anteriormente, não foi identificada nenhuma reação metamórfica que marcasse o início, ou a desestabilização da paragênese principal. Assim, sabe-se apenas que o campo de estabilidade da fácies epídoto-anfibolito está limitado, no lado de baixa temperatura, pelas reações que eliminam a clorita (chlorite-out) principalmente da paragênese das rochas de composição básica.

$\mathrm{O}$ limite superior de estabilidade da clorita está ligado às reações que definem a transição do fácies xistos verdes para o fácies anfibolito e que, por envolverem complexas mudanças na solução sólida das fases minerais coexistentes, têm seu posicionamento no gráfico $\mathrm{P} \times \mathrm{T}$ fortemente influenciado pelas condições de $\mathrm{fO}_{2}$ do metamorfismo (Moody et al. 1983). Normalmente, se usa representar estas reações como de caráter contínuo numa faixa de temperatura cujo intervalo depende da $\mathrm{fO}_{2}$; porém, esta faixa chlorite-decreasing tem seu limite superior (chlorite-out) aparentemente independente da $\mathrm{fO}_{2}$, pois é concordante nas reações experimentalmente controladas que foram realizadas por Liou et al. (1974) e por Moody et al. (1983). Assim, independente da reação metamórfica que se escolha para delimitar o campo de estabilidade da paragênese das rochas máficas, é muito importante averiguar, através da composição mineralógica, qual a condição aproximada de $\mathrm{fO}_{2}$ do metamorfismo.

A presença de exsoluções de hematita+rutilo nos cromititos (Strieder \& Nilson 1992), de rutilo+magnetita nos xistos metassedimentares (Strieder 1989) e, principalmente, de pistacita como importante fase mineral da paragênese das rochas máficas são indicações concretas de que o metamorfismo se processou sob condições de $\mathrm{fO}_{2}$ relativamente elevadas. Sob estas condições, foi selecionada a reação 10 (Fig. 3, Strieder \& Nilson 1992) posicionada próxima ao limite superior de estabilidade da clorita (Liou et al. 1974) para marcar o limite inferior das condiç̃es de $\mathrm{P}$ e de $\mathrm{T}$ do metamorfismo. Esta reação tem uma aplicação mais ampla, na medida em que também pode ser usada para representar a formação do anfibólio presente nas rochas metassedimentares encaixantes (Strieder 1989).

Do outro lado, a reação 11, que marca o limite superior de estabilidade do epídoto sob condições de alta $\mathrm{fO}_{2}$, não pode ser usada como limite superior do fácies epídoto-anfibolito, por que já está dentro do campo geral de estabilidade da estauroHta. $\mathrm{O}$ limite superior das condições de $\mathrm{P}$ e de $\mathrm{T}$ deste fácies metamórfico é dado, então, pelas reações 8 e 9 (Fig. 3, Strieder \& Nilson 1992), que caracterizam o aparecimento da estaurolita sob condições de média a alta $\mathrm{fO}_{2}$ em rochas metassedimentares com elevado conteúdo de $\mathrm{Na}_{2} \mathrm{O}+\mathrm{CaO}$ e alta razão $\mathrm{MgO} / \mathrm{MgO}+\mathrm{FeO}^{*}$; estas reações têm um posicionamento semelhante àquela que marca a formação de forsterita+talco a partir da antigorita, que é a fase mineral estável nos serpentinitos da região.

$\mathrm{O}$ granada + mica+quartzo xisto, como observado na região de Abadiânia (GO), e o muscovita quartzito são as rochas predominantes dos metassedimentos Araxá. Este granada + mica + quartzo xisto, por sua composição química global, é pouco propenso à cristalização de cloritóide e de estaurolita e, portanto, retarda o aparecimento destes minerais índices. No entanto, na região de Ipameri (GO), foram registradas importantes extensões de metassedimentos aluminosos (Dardenne et al. 1992); neste caso, a eliminação da clorita será controlada pelas reações 4 e 5 ('Strieder \& Nilson 1992). A reação 4 , em xistos metassedimentares com relação $\mathrm{Mg}$ / $\mathrm{Mg}+\mathrm{Fe}$ menor do que 0,25 , é mais adequadamente descrita por: - clorita + muscovita $\rightarrow$ estaurolita + biotila + quartzo $+\mathrm{H}_{2} \mathrm{O}$.
Esta reação está definida por condições de pressão e temperatura aproximadamente iguais àquelas definidas pelo traçado das reações 4 e 5 .

As paragêneses metamórficas observadas nas regiões de Abadiânia e de Ipameri estão, portanto, condicionadas a um intervalo de temperatura entre 550 e $600^{\circ} \mathrm{C}$ e de pressão superior a 5 kbar. Estas condições são compatíveis com um metamorfismo do tipo barroviano que foi "estabilizado" na fácies epídoto-anfibolito (grau médio) e não na fácies xisto verde superior (grau baixo), como havia sido anteriormente discutido por Strieder (1989).

PETROQUÍMICA DAS ROCHAS MÁFICAS O reconhecimento deste grupo de rochas como o produto do metamorfismo e da deformação de um protolito gabróico pode ocasionar sérios erros no tratamento petroquímico dos dados analíticos, devido à impossibilidade de se verificar diretamente a existência, ou não, de texturas acumulativas. A existência de texturas acumulativas impede a utilização de uma série de diagramas discriminantes construídos e utilizados para basaltos. A ocorrência de processos de diferenciação relacionados à formação de textura cumulus deve, então, ser testado indiretamente através da utilização dos próprios dados químicos. Desta forma, segue-se a orientação de Pearce \& Cann (1973) e de Pearce \& Norry (1979), que construíram diagramas discriminantes do ambiente tectônico para rochas basálticas cujo conteúdo de $\mathrm{CaO}+\mathrm{Al}_{2} \mathrm{O}_{3}$ estava entre 12 e $20 \%$. Conteúdos fora destes limites não indicam, necessariamente, a existência de processos acumulativos, mas são excluídos de maneira a se obter uma variação composicional que fique restrita ao campo dos basaltos.

As análises químicas de epídoto-anfibólio xisto alojados nos metassedimentos Araxá possuem o conteúdo de $\mathrm{CaO}+\mathrm{Al}_{2} \mathrm{O}_{3}$ dentro dos limites especificados e plotam muito próximo da composição média dos basaltos meso-atlânticos (MORB) em diagramas $\mathrm{MgO}-\mathrm{Al}_{2} \mathrm{O}_{3}-\left(\mathrm{Na}_{2}+\mathrm{K}_{2} \mathrm{O}\right)$, ou $(\mathrm{CaO})$ (Fig. 11, Strieder \& Nilson 1992). O padrão de ETR (Fig. 1), por sua vez, mostra um alto conteúdo global de ETR e a inexistência de anomalias positivas de Eu (presença de plagioclásio cumulus), ou de anomalias positivas de ETRP (presença de piroxênios cumulus). Desta forma, as rochas máficas parecem representar os níveis plutônicos superiores da coluna ofiolítica, onde também há a presença de rochas félsicas (plagiogranitos).

A conclusão anterior dirige a investigação petroquímica, primeiramente, à utilização do discriminante $\mathrm{TiO}_{2} \times \mathrm{FeO} *$ / $\left(\mathrm{FeO}^{*}+\mathrm{MgO}\right)$, introduzido por Serri (1981) para a classificação de complexos gabróicos de alto ou de baixo $\mathrm{TiO}_{2}$. Esse discriminante (Fig. 2) sugere que, no conjunto, as rochas máficas pertencem aos complexos do tipo alto $\mathrm{TiO}_{2}$. No entanto, pode-se observar dois agrupamentos: 1. os corpos de epídoto-anfibólio xisto de Abadiânia, que possuem um baixo conteúdo global de $\mathrm{TiO}_{2}$, semelhante àquele dos complexos ofiolíticos de Troodos e de Vourinos; e 2. os corpos máficos de Ipameri (GO), que possuem um alto conteúdo de $\mathrm{TiO}_{2}$.

Estes resultados mostram a necessidade de se aprofundar a verificação da ocorrência de processos acumulativos nas rochas máficas; pode-se, então, utilizar, comparativamente, as investigações de Pearce \& Flower (1977). As figuras 3A-B apresentam, respectivamente, os diagramas $\mathrm{Al}_{2} \mathrm{O}_{3} / \mathrm{TiO}_{2}$ x Ti e $\mathrm{G} / \mathrm{Ti}$ x Ti daqueles autores; nestes diagramas, os epídoto-anfibólio xistos se colocam ao longo de um trend de fracionamento compatível com as variações inerentes aos líquidos magmáticos. As amostras com teores mais baixos de $\mathrm{TiO}_{2}$ parecem, contudo, sugerir uma pequena acumulação de plagioclásio. Porém, as relações Ce/Sm x Sm e Sm/Yb x Sm (Figuras 3C-D), que permitiram a Pearce \& Flower (1977) separar os efeitos de processos acumulativos, do fracionamento e de variações na composição inicial do magma, mostram, no entanto, que os epídoto-anfibólio xistos de Abadiânia plotam no campo correspondente aos basaltos de cadeia meso-atlântica. 


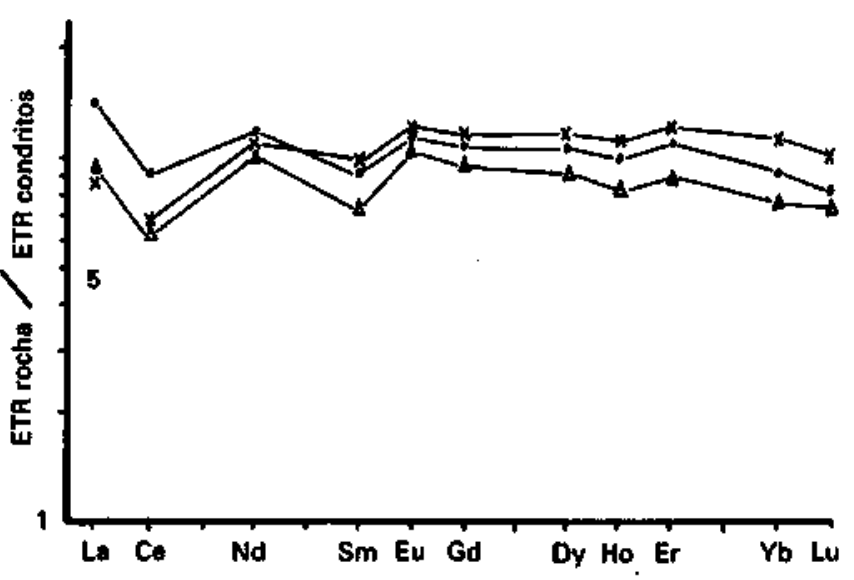

Figura 1 - Padrão ETR para o epídoto-anfibólio xisto. Normalização realizada com dados de Masuda et al. (1973) divididos por 1.2 para aproximação com os condrítos compostos. $O$ valor de Ho é de Evensen et al. (1978) e multiplicado por 1,28 pela mesma razão. xAB-19a, - AB-59b, $\triangle A B-59 d$ Figure 1 - REE pattern for the epidote-amphibole schist Normalization used Masuda et al. (1973) values' divided by 1,2 to approximate the compound chrondrite values. Ho value is from Evensen et al. (1978)multipledby 1,28 for the same reason, $\mathrm{x} A B-19 \mathrm{a}, \bullet \mathrm{AB}-59 \mathrm{~b}, \Delta \mathrm{AB}-59 \mathrm{~d}$

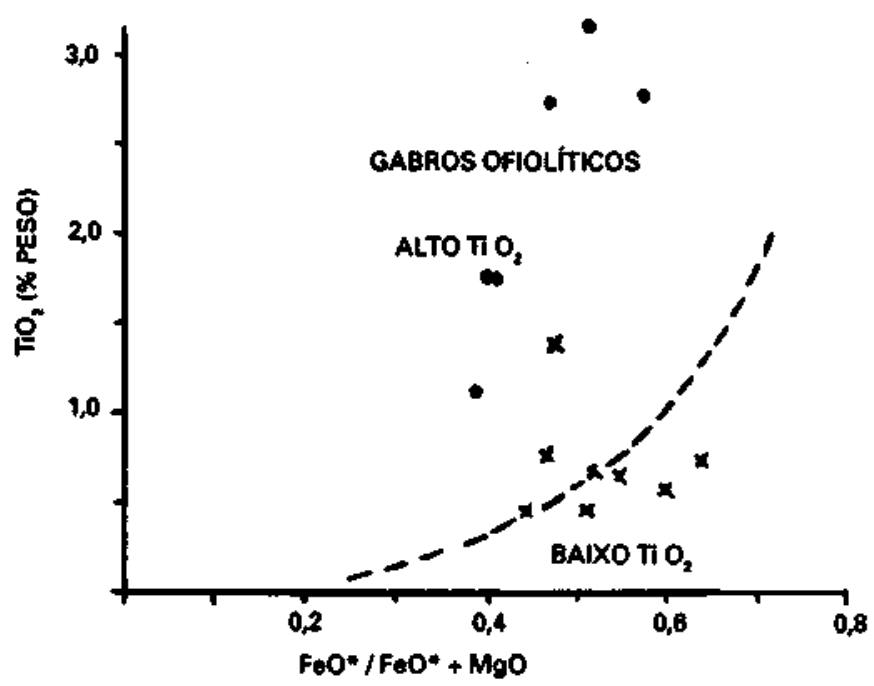

Figura 2-Diagrama $\mathrm{TiO}_{2} x \mathrm{FeO} * /(\mathrm{FeO} *+\mathrm{MgO})$ que diferencia rochas gabróicas de alto e de baixo $\mathrm{TiO}_{2}$ dos complexos ofiolíticos (Serri 1981). Amostras de Abadiânia (x) e de Ipameri $(\bullet)$

Figure $2-\mathrm{TiO}_{2} \times \mathrm{FeO}^{*} /(\mathrm{FeO} *+\mathrm{MgO})$ diagram to differentiate high and low $\mathrm{TiO}_{2}$ gabbroic rocks of the ophiolitic complexes (Serri 1981). Samples from Abadiânia (x) and Ipameri $(\bullet)$

Confirma-se, assim, a natureza nãoacumulativa das rochas máficas e pode-se considerá-las como possíveis representantes do magma pouco fracionado, que anteriormente formou as rochas acumulativas de urna seqüência ofiolítica hoje desmembrada. As análises químicas destas rochas podem, então, ser utilizadas para averiguar as suas afinidades geoquímicas e o ambiente tectônico onde foram geradas.

A Figura 4 apresenta uma série de diagramas baseados em elementos imóveis, que foram introduzidos por Pearce \& Cann (1973), por Pearce \& Norry (1979) e por Shervais (1982) para diferenciar rochas basálticas toleíticas geradas em sistemas de arcos-de-ilhas daquelas geradas em cadeias meso-oceânicas, ou em platôs oceânicos (basaltos alcalinos).
Embora se disponha de poucas amostras analisadas, as rochas máficas alojadas nos metassedimentos Araxá revelamse geoquimicamente coerentes na maioria dos diagramas utilizados e apontam para dois agrupamentos de afinidade toleítica: 1. aquelas geradas em sistemas de arcos-de-ilhas (Abadiânia) e 2. aquelas relacionadas a fundo oceânico (Ipameri). Estes agrupamentos já eram anteriormente sugeridos pelo conteúdo de $\mathrm{TiO}_{2}$ (Fig. 2).

O padrão ETR dos corpos máficos da região de Abadiânia (Fig. 1) é aproximadamente horizontal e tem um conteúdo global de ETR em tomo de 10 vezes aquele dos condritos. A pequena variação nos padrões ETR é reflexo da variação pouco acentuada dos elementos maiores dos epídoto-anfibólio xisto (Fig. 11, Strieder \& Nilson 1992). Estas características de magma pouco diferenciado também foram sugeridas pelas figuras 3C-D e vão fornecer parâmetros químicos mais claros para a utilização do padrão ETR como indicador petrogenético. A inexistência de um nítido empobrecimento em ETRL para rochas tão básicas quanto as de Abadiânia exclui uma afinidade com toleítos mesoceânicos normais (Saunders 1984) e dirige a relação para os toleítos meso-oceânicos de tipo transicional, ou para os toleítos de arcos-de-ilhas (Cullers \& Graff 1984). As indicações fornecidas pelos diagramas discriminantes utilizados são, portanto, mais favoráveis com a interpretação de que os corpos máficos de Abadiânia são toleítos relacionados a arcos-de-ilhas.

DISCUSSÃO DA IMPLICAÇÃO TECTONIC A DA PETROQUÍMICA A indicação de uma composição toleítica relacionada a arcos-de-ilhas para as rochas máficas da região de Abadiânia pode causar alguma estranheza na medida em que tanto os corpos máficos, quanto os corpos ultramáficos são interpretados como fragmentos tectônicos de uma estrutura ofiolítica que, hoje, constitui parte integral da melange ofiolítica reconhecida no Estado de Goiás (Strieder \& Nilson 1991). Neste sentido, serão feitas algumas considerações a respeito da interrelação dos dados obtidos nestes primeiros trabalhos específicos e do posicionamento tectônico sugerido por estes dados. Está-se, contudo, perfeitamente conciente de que é necessário um volume maior de dados estruturais e petrológicos a nível regional para que se possa interpretar seguramente o condicionamento tectônico global da melange ofiolítica.

Tem-se, usualmente, distinguido duas situações tectônicas onde os complexos, ou os corpos ofiolíticos aparecem nos diversos cinturões colisionais reconhecidos (Apalachiano: Williams \& Talkington 1977, Coish \& Church 1979, Coish et al. 1982; Mediterrâneo: Smewing et al. 1975, Pearce 1980): 1. bacias oceânicas, ou bacias marginais maduras e 2 . bacias marginais jovens, arcos-de-ilhas, ou bacias pós-arco. Estes posicionamentos tectônicos podem ser distingúidos pelas características petroquímicas das rochas máficas e ultramáficas e, também, pelas suas características litológicas e estruturais. As rochas máficas do primeiro grupo possuem características petroquímicas que variam entre basaltos meso-ceânicos normais e basaltos oceânicos alcalinos (within-plate basalts), enquanto aqueles do segundo grupo apresentam afinidades geoquímicas entre basaltos meso-oceânicos normais e basaltos de arcos-de-ilhas.

A informação petroquímica obtida a partir das rochas máficas da região de Abadiânia (GO) parece ser consistente com os dados registrados pelas rochas ultramáficas e pelos cromititos, por que a unidade mantélica que serve como substrato neste tipo de posicionamento tectônico é normalmente composta por tectonitos de composição harzburgítica, que passaram por vários episódios de fusão parcial e são, portanto, empobrecidos em muitos elementos químicos. Dentro destas características gerais, pode-se compreender o significado da afinidade geoquímica registrada pelas rochas máficas de Abadiânia.

A boa interrelação dos dados petroquímicos na região de Abadiânia não deve, contudo, ser tomada como uma 

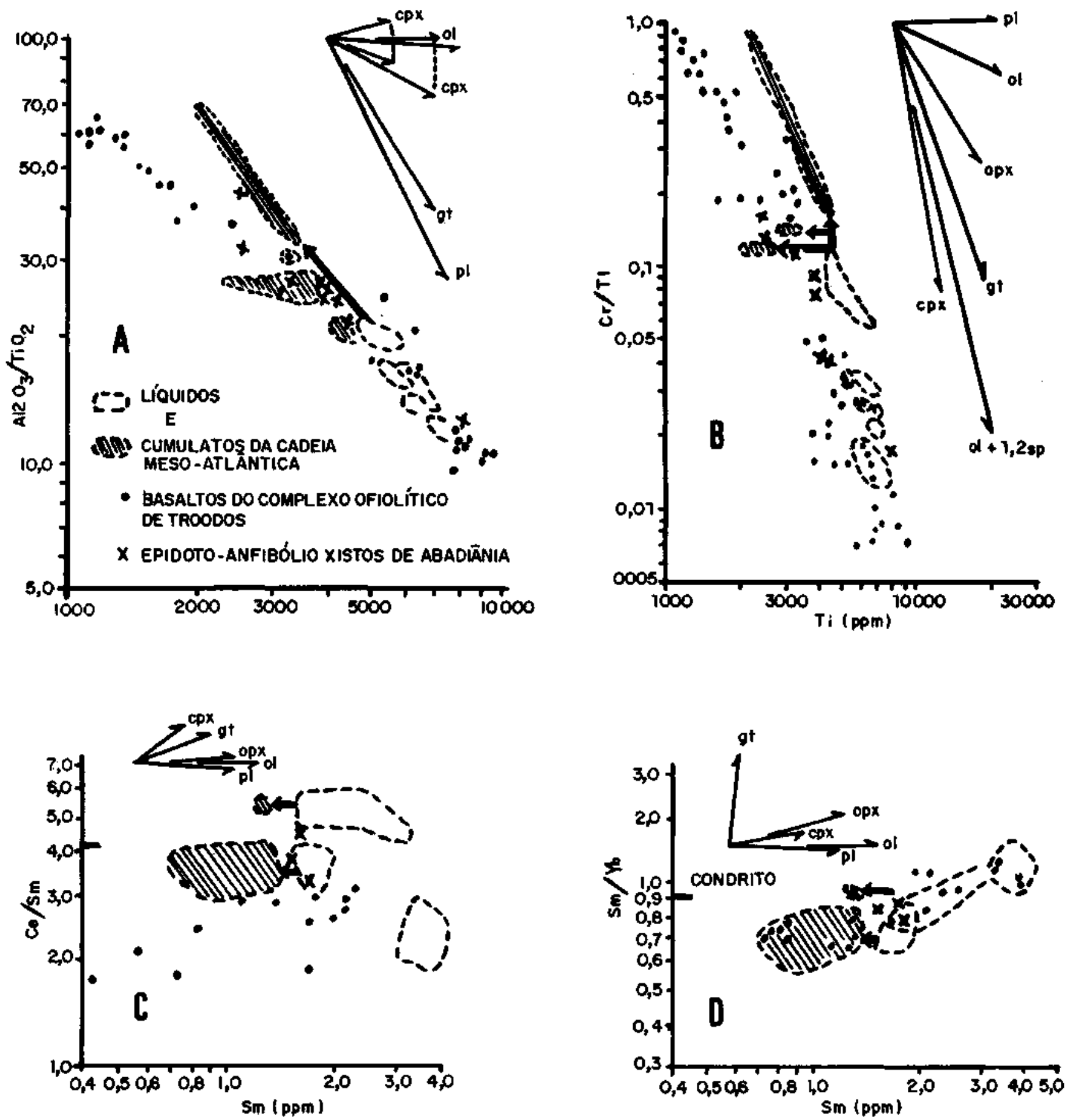

Figura 3 - Diagrama de variação do $\mathrm{Ti}^{4+}$ contra as razões (A) $\mathrm{Al}_{2} \mathrm{O}_{3} / \mathrm{TiO}_{2}$ e (B) Cr/Ti e do $\mathrm{Sm}$ contra as razões (C) Ce/Sm e (D) $\mathrm{Sm} / \mathrm{Yb}$

Figure 3 - Variation diagram of $\mathrm{Ti}^{4+}$ against the (A) $\mathrm{Al}_{2} \mathrm{O}_{3} / \mathrm{TiO}_{2}$ and (B) $\mathrm{Cr} / \mathrm{Ti}$ ratios and $\mathrm{Sm}$ against the (C) $\mathrm{Ce} / \mathrm{Sm}$ e (D) $\mathrm{Sm} / \mathrm{Yb}$ ratios

interpretação conclusiva e abrangente para a melange ofiolítica presente nos metassedimentos Araxá. É muito importante terse em mente que estes dados representam apenas os resultados das primeiras investigações específicas para elucidar o significado tectônico global desta associação petrotectônica. A natureza fragmentária dos corpos alojados nos metassedimentos Araxá é, certamente, um fator limitante na investigação do significado tectônico das variações composicionais apresentadas. Assim, é perfeitamente admissível a pre- sença de rochas provenientes de várias posições tectônicas alojadas como fragmentos exóticos na melange ofiolítica. Este pode ser o caso dos corpos máficos da região de Ipameri (GO), que apresentam uma afinidade geoquímica com basaltos toleíticos normais (MORB); estas características geoquímicas podem, por outro lado, estar indicando simplesmente as variações composicionais das rochas máficas relacionadas a bacias marginais jovens, ou sistemas de arcos-de-ilhas. 

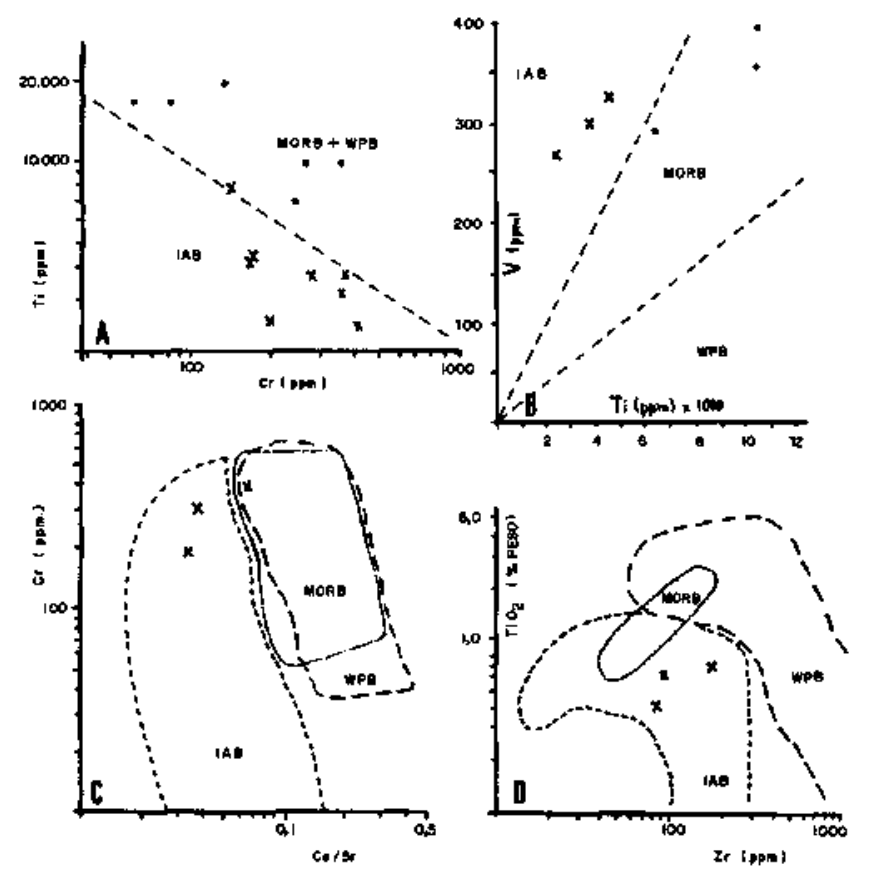

Figura 4 - Diagramas discríminantes de ambiente tectônico de rochas basálticas utilizados nos corpos máficos: (A) Ti x Cr, (B) $\mathrm{V} x \mathrm{Ti}$, (C) $\mathrm{Cr} \times \mathrm{Ce} / \mathrm{Sr}$ e (D) $\mathrm{TiO}_{2} \times \mathrm{Zr}$. Amostras de Abadiania $(x)$ e de Ipameri $(\bullet)$

Figure 4 - Tectonic setting discriminant diagrams of basaltic rocks used in the mafic bodies: (A) $\mathrm{Ti} x \mathrm{Cr}$, (B) $\mathrm{V} x \mathrm{Ti}$, (C) $\mathrm{Cr} x$. $\mathrm{Ce} / \mathrm{Sr} \mathrm{e}$ (D) $\mathrm{TiO}_{2} x \mathrm{Zr}$. Samples from Abadiânia (x) and Ipameri $(\bullet)$

CONCLUSÕES O estudo petrográfico dos corpos máficos alojados nos metassedimentos Araxá permitiu, até o momento, reconhecer texturas faneríticas reliquiares e miloníticas; estas feições texturais apontam um protolito gabróico para os corpos máficos aqui analisados. A intensa milonitização regional $\left(D_{1}\right)$ dá origem a texturas predominantemente nematoblásticas a granoblásticas elongadas, que ocorrem em bandas milimétricas formadas por três distintas paragêneses metamórficas; estas bandas de diferentes paragêneses associam-se duas a duas para formar um outro bandamento, desta vez de escala centimétrica.
A identificação de uma mesma paragênese mineral principal e a observação das relações de contato entre as fases minerais das superfícies deformacionais mais desenvolvidas nos corpos máficos permitiram indicar que o processo deformacional desenvolvido na região ocorreu sem que houvesse mudança significativa nas condições de T. A ausência de clorita da paragênese metamórfica principal fez com que ela fosse relacionada à fácies epídoto-anfibolito (grau médio) e as condições de $\mathrm{T}$ e de $\mathrm{P}$ fossem, respectivamente, estimadas em: $550-600^{\circ} \mathrm{C}$ e $>5$ kbar.

A natureza gabróica dos corpos máficos poderia sugerir a presença de texturas e de estruturas acumulativas e, neste caso, não permitir a utilização das análises químicas em investigações de sua natureza petrotectônica. Foi realizada uma avaliação indireta da presença de processos acumulativos pelo uso de diagramas químicos e não se observou qualquer disparidade química que pudessem ser relacionadas com tais processos. Deste modo, uma série de diagramas discriminantes, que empregam elementos menores e traços, indicou que: 1. os corpos máficos de Abadiânia são toleítos relacionados a bacias marginais jovens, ou a sistemas de arco-de-ilhas, ao passo que 2 . os corpos máficos da região de Ipameri (GO) são toleítos normais relacionados a fundo oceânico.

Os primeiros dados petroquímicos de fragmentos tectônicos de melange ofiolítica nos metassedimentos Araxá sugerem que, na região de Abadiânia (GO), eles derivam de bacias marginais relacionadas a arcos magmáticos, por que têm composição harzburgítica (corpos de serpentinito) e toleítica alto-K (corpos máficos). As variações composicionais registradas nas rochas máficas deste posicionamente geotectônico justificam a presença de toleítos normais (MORB) associados aos toleítos alto-K. Há de se ressaltar, contudo, a possibilidade de serem identificados outros tipos de fragmentos tectonicamente alojados nos metassedimentos; no caso da melange ofiolítica, poderão ainda ser identificados fragmentos exóticos, não necessariamente relacionados ao ciclo geotectônico gerador da melange ofiolítica.

Agradecimentos Os autores gostariam de agradecer à Metais de Goiás S.A. pelo suporte financeiro aos trabalhos de campo em Abadiânia durante o período 1987-1988. Ao CNPq (processo 408044/86.1) pela viabilização das análises químicas relativas aos corpos na região de Abadiânia (GO). Ao Prof. Marcel A. Dardenne, Coord, do Trabalho Final de 1991 (IGeo - UnB), por permitir a publicação dos dados químicos referentes à região de Ipameri (GO).

\section{REFERÊNCIAS BIBLIOGRÁFICAS}

ARAÚJO, V.A.; MATIAS, P.V.B.; GODOI, H.O.; ARAÚJO, E.S.; MORETON, L.C.; SILVA, M.A. 1980. Projeto Pontalina - Relatório da Fase I Rio de Janeiro, Convênio DNPM/CPRM-MME. v. 1,227 p.

BATISTA, M.B. 1969. Projeto Goiânia - Folha Morrinhos. Relatório Preliminar. Rio de Janeiro, Convênio PROSPEC/DNPM-MME. $31 \mathrm{p}$.

BECCALUVA, L.; OHNENSTETTER, D.; OHNENSTETTER, M. 1979. Geochemical discrimination between ocean-floor and island-arc tholeiites - application to some ophiolites. Can. J. Earth Sci., 16:1874-1882.

BERBERT, C.O.; CORRÊA, J.A.; MELO, J.C.R. 1970. Geologia da Área de Interlândia-Abadiânia, Goiás. Rio de Janeiro, DNPM-MME. 59 p. (Boletim 135)

BOAVENTURA, G.R. \& HIRSON, J.R. 1987. Amostras de referência geoguímica para controle de análises de rochas. In: CONGR. BRAS. GEOQUIM., 1. Porto Alegre, 1987. Anais... Porto Alegre, SBGq. v. 2, p. 321-326.

COISH, R. A. \& CHURCH, W.R. 1979. Igneous geochemistry of mafic rocks in the Betts Cove Ophiolite, Newfoundland. Contr. Mineral. Petrol., 70(1):29-39.

COISH, R.A.; HICKEY, R.; FREY, FA. 1982. Rare earth element geochemistry of the Betts Cove Ophiolite, Newfoundland: complexities in the ophiolite formation. Geochim. Cosmochim. Acta, 46(11): 2117-2134.

CORRÊA, J. \& BITTENCOURT, C.M. 1968. Mapeamento Geológico da área Goiânia-Bonfinópolis, Goiás. Rio de Janeiro, DNPM-MME. 71 p. (Boletim 134).
CULLERS, R.L. \& GRAF, J.L. 1984. Rare earth elements in igneous rocks of continental crust: predominantly basic and ultrabasic rocks. In: HENDERSON, P. ed. Rare Earth Element Geochemistry. Amsterdan, Elsevier. p. 237-274.

DARDENNE, M.A.; FUCK, R.A.; MENEZES, P.R.; STRIEDER, A.J.; PIMENTEL, M.M.; VIANA, M.G.; RIBEIRO, R.K.; ROCHA, A.C.D.; FUCK, R.F.; OLIVEIRA, R.N.; ARAÚJO, A.H.; JANKOZ, J.; FLEURY, D.F.R.; MIRANDA, G.H.B.; RODRIGUES, J.B.; QUEIROZ, C.L.; MELO, C.P.; REGO, F.M.S.; M. FILHO, L.S.; TOLEDO, A.R.; FILLIZOLA, N.P., Jr.; RESENDE, L.; ARAKI, M.S.; BLUM, M.L.B. 1992. Geologia do Projeto Sucuri, região de Ipameri, sudeste do Estado de Goiás. In: CONGR. BRAS. GEOL., 37. São Paulo, 37. Resumos Expandidos... São Paulo, SBG. v. 2, p. $149-150$

EVENSEN, N.M.; HAMILTON, P.J.; O'NIONS, R.K. 1978. Rare-earth abundances in chondritic meteorites. Geochim. Cosmochim. Acta, 42:1199-1212.

LIOU, J.G.; KUNIYOSHI, S.; ITO, K. 1974. Experimental studies of the phase relations between greenschist and amphibolite in a basaltic system. Am. 3 . Sci., 274(5):613-632.

MASUDA, A.; NAKAMURA, N.; TANAKA, T. 1973. Fine structures of mutually normalized rare-earth patterns of chrondrites. Geochim. Cosmochim. Acta, 37:239-248. 
MOODY, J.B.; MEYER, D.; JENKINS, J.E. 1983. Experimental characterization of the greenschist/amphibolite boundary in mafic systems. Am. J Sci.,283(1):48-93.

NILSON, A A · CORREA, J A ; MELO J C R ; FIGUEIREDO, A N · REIS, A.G.L.; BAETA., J.D.A., Jr; JUSTO, LJ.E.C.; LESSA SOBRINHO, M. 1969. Geologia da região de Cromínia-Pontalina, Goiás. In: CONGR. BRAS. GEOL., 23. Salvador, 1969. Resumos... Salvador, SBG. p. 70-71.

PEARCE, J. A. 1980. Geochemical evidence for the genesis and eruptive setting of lavas from Tethyan ophiolites. In: PANAYIOTON, A. ed. Proceeding of the International Ophiolite Symposium. Cyprus, 1979. p. 261-272.

PEARCE, J.A. \& CANN, J.R. 1973. Tectonic setting of basic volcanic rocks determined using trace element analysis. Earth Planet. Sci. Lett., 19(2):290-300.

PEARCE, J A \& FLOWER, M.F.J 1977. The relative importance of petrogenetic variables in magma genesis at accreting plate margins: a preliminary investigation. J. Geol. Soc. London, 134(1): 103-127.

PEARCE, J.A. \& NORRY, M.J. 1979. Petrogenetic implications of Ti, Zr, Y and $\mathrm{Nb}$ variations in volcanic rocks. Contr. Mineral. Petrol 69(1):33-47.

SAUNDERS, A.D 1984. The rare earth element characteristics of igneous rocks from the ocean basins. In: HENDERSON, R ed. Rare Earth Element Geochemistry. Amsterdan, Elsevier. p 205-236.

SERRI, G. 1981. The petrochemistry of ophiolite gabbroic complexes: a key for the classification of ophiolites into low-Ti and high-Ti types. Earth Planet. Sci. Lett., 52(1):203-212.

SHERVAIS, J.W. 1982. Ti-V plots and the petrogenesis of modern and ophiolitic lavas. Earth Planet. Science Lett., 59(1):101-118.

SMEWING, J.D.; SIMONIAN, K.O. \& GASS, I.G. 1975. Metabasalts from the Troodos Massif, Cyprus: genetic implications deduced from petrography and trace element geochemistry. Contr. Mineral. Petrol., 51(1):49-64.

STRIEDER, A.J. 1989. Geologia, Petrologia e Tectônica dos Corpos de Serpentinito e Rochas Encaixantes, Abadiânia (GO). Brasília. 208 p. (Dissertação de Mestrado, IG/UnB)

STRIEDER, AJ. 1990. Análise estrutural da região de Abadiânia (GO). Rev. Bras. Geoc., 20(1-4):239-257.

STRIEDER, AJ. \& NILSON, A.A. 1992. Melange ofiolítica nos metassedimentos Araxá em Abadiânia (GO) e implicações tectônicas regionais. Rev. Bras. Geoc., 22(2):204-215.

STRIEDER, AJ. \& NILSON, A.A. 1992 Estudo petrológico de alguns fragmentos tectônicos da melange ofiolítíca em Abadiânia (GO): I - O protolito dos corpos de serpentinito. Rev. Bras. Geoc., 22(3): 338-352.

STRIEDER, AJ. \& NILSON, A.A. 1992 Estudo petrológico de alguns fragmentos tectônicos da melange ofiolítica em Abadiânia (GO): $\mathrm{n}$ - As cromitas primárias e as suas transformações metamórficas. Rev. Bras. Geoc., 22(3):353-362.

WILLIAMS, H. \& TALKINGTON, R.W. 1977. Distribution and tectonic setting of ophiolite and ophiolitic melanges in the Appalachian orogen. IN: R.G. COLEMAN \& W.P. IRWIN eds. North American Ophiolites. Oregon, Dep. Geology and Mineral Industries, p. 11 (Bull. 95)

MANUSCRITO A727 Recebido em 19 de marco de 1992 Revisão do autor em 2 de julho de 1992 Revisão aceita em 14 de julho de 1992 